\title{
Ship-borne electromagnetic induction sounding of sea-ice thickness in the southern Sea of Okhotsk
}

\author{
Shotaro UTO, ${ }^{1}$ Takenobu TOYOTA, ${ }^{2}$ Haruhito SHIMODA, ${ }^{1}$ Kazutaka TATEYAMA, ${ }^{3}$ \\ Kunio SHIRASAWA ${ }^{2}$ \\ ${ }^{1}$ National Maritime Research Institute, 6-38-1 Shinkawa, Mitaka, Tokyo 181-0004, Japan \\ E-mail: uto@nmri.go.jp \\ ${ }^{2}$ Institute of Low Temperature Science, Hokkaido University, Sapporo 060-0819, Japan \\ ${ }^{3}$ Kitami Institute of Technology, Koen-cho 165, Kitami 090-8507, Japan
}

\begin{abstract}
Recent observations have revealed that dynamical thickening is dominant in the growth process of sea ice in the southern Sea of Okhotsk. That indicates the importance of understanding the nature of thick deformed ice in this area. The objective of the present paper is to establish a ship-based method for observing the thickness of deformed ice with reasonable accuracy. Since February 2003, one of the authors has engaged in the core sampling using a small basket from the icebreaker Soya. Based on these results, we developed a new model which expressed the internal structure of pack ice in the southern Sea of Okhotsk, as a one-dimensional multilayered structure. Since 2004, the electromagnetic (EM) inductive sounding of sea-ice thickness has been conducted on board Soya. By combining the model and theoretical calculations, a new algorithm was developed for transforming the output of the EM inductive instrument to ice + snow thickness (total thickness). Comparison with total thickness by drillhole observations showed fair agreement. The probability density functions of total thickness in 2004 and 2005 showed some difference, which reflected the difference of fractions of thick deformed ice.
\end{abstract}

\section{INTRODUCTION}

The Sea of Okhotsk is regarded as the southernmost sea-ice zone in the Northern Hemisphere except for areas of coastal freezing. It is recognized that the growth and decay of sea ice is sensitive to climate change on a global scale. Hence a lot of research has been conducted in terms of the interannual variability of sea ice in the Sea of Okhotsk (e.g. Parkinson and others, 1999). Most research has dealt not with volume but with area of sea ice. This is due to difficulties in monitoring sea-ice thickness on a large geophysical scale by either field or satellite observations. Recently, many observations of sea-ice thickness have been conducted in the southern Sea of Okhotsk. In 1991, the National Maritime Research Institute (NMRI) of Japan initiated ship-based video observations of sea-ice thickness on board the icebreaker Soya of the Japan Coast Guard (Uto and others, 1999). Since 1996, the Institute of Low Temperature Science (ILTS), Hokkaido University, has conducted video observations on board Soya in early to mid-February. Based on these ship-based data, Toyota and others (2004b) proposed the mechanism of the development of relatively thin ice as a 'rafting cycle'. The ILTS has also conducted ship-based visual observations. Hourly observations of sea-ice and meteorological conditions were conducted in accordance with the protocol developed by the Scientific Committee on Antarctic Research (SCAR)/ Antarctic Sea Ice Processes and Climate (ASPeCt) program (Worby, 1999). It was found that the deformed ice such as ridged or hummocked ice comprises up to about $70 \%$ of the total sea-ice volume (Toyota, unpublished information). Fukamachi and others (2003) deployed a moored iceprofiling sonar near the coast of Hokkaido to observe the draft distribution of sea ice. It was reported that the volumetric fraction of deformed ice is about $70 \%$ and $90 \%$ of total volume in February and March, respectively. Thus, understanding the thickness distribution of deformed ice is a key issue for estimating sea-ice volume.

The objective of the present study is to establish a shipbased method for observing the thickness of deformed ice with reasonable accuracy. It should be noted that deformed ice is defined as ridged or hummocked ice in this study. Rafted ice is included in the category of level ice. Since 2003, one of the authors has engaged in the core sampling using a small basket from Soya (Toyota and others, 2004a). Since 2004, a ship-borne electromagnetic inductive (hereafter denoted as SEM) instrument has been used for observing ice + snow thickness (total thickness). Based on the core analysis, the authors developed a model expressing the distribution of direct-current conductivity as a onedimensional multilayer model. Combining this model and theoretical calculation, a new algorithm was developed for transforming the output of SEM instruments to the thickness of both deformed and level ice in the southern Sea of Okhotsk.

\section{MEASUREMENT}

SEM observations were conducted from 7 to 13 February 2004 and from 12 to 16 February 2005. Figure 1 indicates the tracks of Soya during SEM observations in 2004 and 2005. Sea ice normally begins to cover the southern Sea of Okhotsk in late January and reaches a maximum at the end of February. Thus these observations were conducted during the ice-growth period. Figure 2 shows the sites of core sampling. In 3 years, 26 ice cores were sampled. Among them, 12 cores were sampled from deformed ice floes. They cover an extensive area below $45.5^{\circ} \mathrm{N}$. This area is defined as the southern Sea of Okhotsk in this study. 


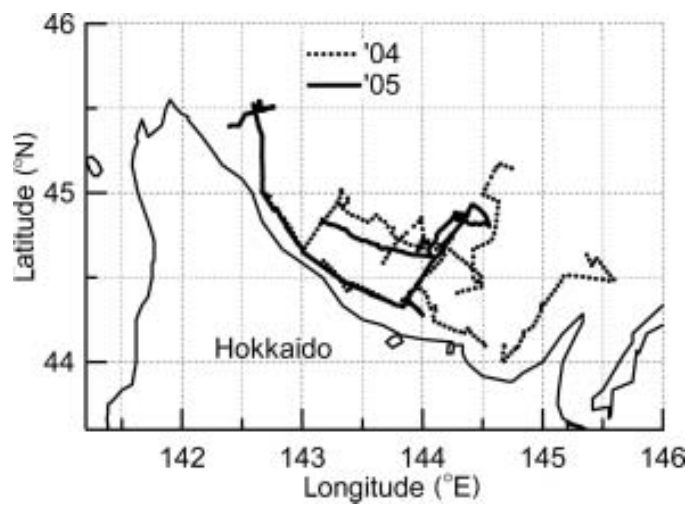

Fig. 1. Location of SEM observations. Dotted and solid lines indicate the track of icebreaker Soya during SEM observations in 2004 and 2005, respectively.

\section{SEM observations}

SEM observation of sea-ice thickness was initiated by Haas (1998) in the Bellingshausen and Amundsen Seas, Antarctica. A portable, single-frequency electromagnetic (EM) sensor (EM31/ICE, Geonics Ltd.) is used to measure the distance $\left(Z_{\mathrm{E}}\right)$ from the sensor to the bottom of sea ice, i.e. surface of sea water. Figure 3 shows the schematic of how the EM sensor measures total thickness. The EM sensor has two coils, a transmitter $\left(T_{X}\right)$ and receiver $\left(R_{X}\right)$ coil, at each end. A primary EM field emitted by $T_{X}$ mostly penetrates snow and ice and induces an eddy current near the seawater surface. This is due to the high contrast in conductivity between resistive sea ice and conductive sea water. A secondary EM field caused by this eddy current is detected by $R_{X}$. The ratio of intensities between the primary $\left(H_{\mathrm{P}}\right)$ and secondary EM field $\left(H_{\mathrm{S}}\right)$ is approximately related to the apparent conductivity $\left(\sigma_{\mathrm{a}}\right)$ in a uniform half-space:

$$
\sigma_{\mathrm{a}}=\frac{4000}{2 \pi \mu_{0} f_{s^{2}}} \operatorname{Im}\left(\frac{H_{\mathrm{S}}}{H_{\mathrm{P}}}\right) .
$$

Here $\mu_{0}$ is magnetic permeability of free space and $f$ and $s$ are frequency $(9.8 \mathrm{kHz})$ and coil spacing $(3.66 \mathrm{~m})$, respectively. Transformation of $\sigma_{\mathrm{a}}$ into $Z_{\mathrm{E}}$ can be obtained either empirically or theoretically. The EM instrument can work in either the vertical coplanar (VCP) or the horizontal coplanar (HCP) coil configuration. The authors selected VCP in terms of its small footprint size (Kovacs and others, 1995). A laser

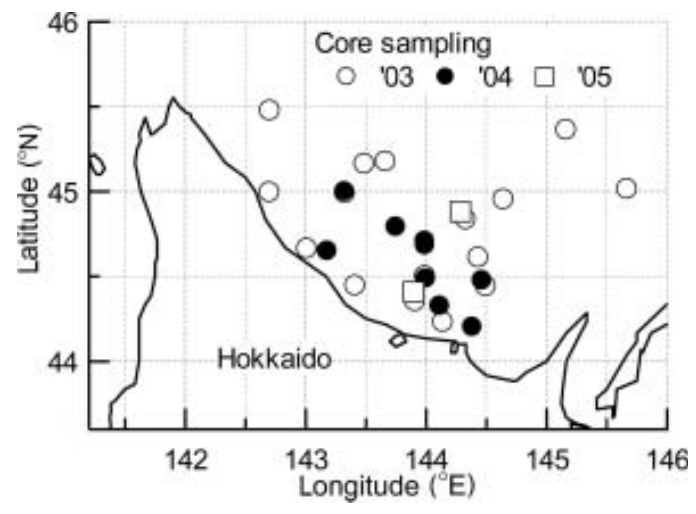

Fig. 2. Locations of sea-ice core sampling. Empty and filled circles denote the locations of observations in 2003 and 2004, respectively. Empty squares indicate the locations of observations in 2005.

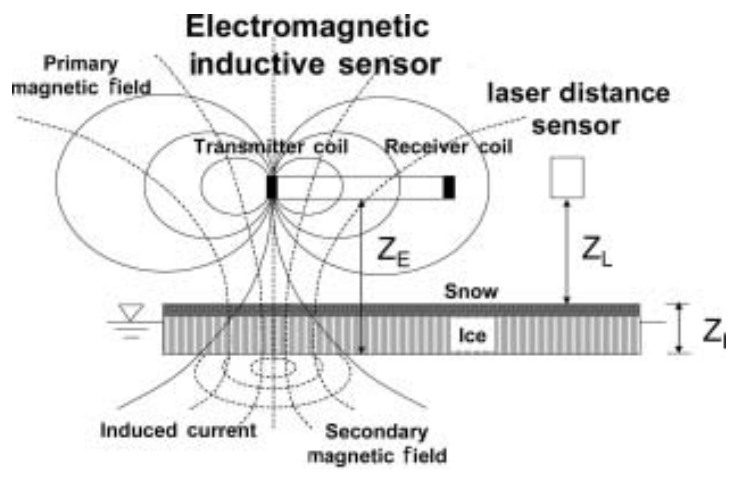

Total thickness : $Z_{1}=Z_{E}-Z_{L}$

Fig. 3. Principle of EM observation of total thickness of sea ice.

distance sensor (LD90-3100HS, Riegl) detects the distance from the sensor to the surface of ice or snow, $Z_{\mathrm{L}}$. Subtracting $Z_{\mathrm{L}}$ from $Z_{\mathrm{E}}$ gives total thickness, $Z_{\mathrm{I}}$.

The output of the EM instrument was calibrated over ice, nilas and sea water by the stepwise changes of sensor height. The over-sea-water calibration was conducted twice in 2004 and once in 2005. In 2005, over-nilas calibration was conducted once. In the over-ice calibration, drillhole observations on ice were also conducted for determining total thickness within the footprint of the sensor. The over-ice calibration was conducted twice in 2004 and once in 2005.

\section{Core sampling}

The sea-ice thickness, snow depth and ice temperature were observed in situ. Measurement of salinity and density, thickand thin-section analysis were conducted at ILTS. The icecore sampling method is described in detail in Toyota (2004a).

\section{DATA REDUCTION Procedure}

A one-dimensional, multilayer model is used for transforming $\sigma_{\mathrm{a}}$ into $Z_{\mathrm{E}}$. In general, the conductivity of sea ice $\left(\sigma_{\text {ice }}\right)$ is small compared to that of sea water $\left(\sigma_{\text {water }}\right)$. For example, Haas (1998) reported that $\sigma_{\text {ice }}$ of the arctic sea ice was typically $0-30 \mathrm{mS} \mathrm{m}^{-1}$ and $\sigma_{\text {water }}$ varies from 2300 to $2900 \mathrm{mS} \mathrm{m}^{-1}$. Therefore in some studies, the influence of $\sigma_{\text {ice }}$ on the transformation from $\sigma_{\mathrm{a}}$ to $Z_{\mathrm{E}}$ is neglected. However, deformed ice contains sea-water- or slush-filled gaps with high conductivity.

Haas (1998) modeled a high-conductivity layer within highly rotten ice of the summer Antarctic. He treated such ice as a one-dimensional, four-layer model to derive a transformation formula from $\sigma_{\mathrm{a}}$ into $Z_{\mathrm{E}}$. A high-saline, slushand sea-water-filled gap near the ice surface was modeled based on the drillhole observations. Tateyama and others (2004) proposed a multi-rafted model expressing slush- and sea-water-filled gaps inside deformed ice in the Antarctic. Their model was derived by fitting the EM responses. In the present study, the authors analyzed core data to obtain a semi-empirical model for deriving total thickness of both deformed and level ice from SEM responses. Figure 4 shows the flow chart. The thicknesses of ice block and porosity, which are determined from core data, give the structure model. The conductivity model is derived from core analysis 


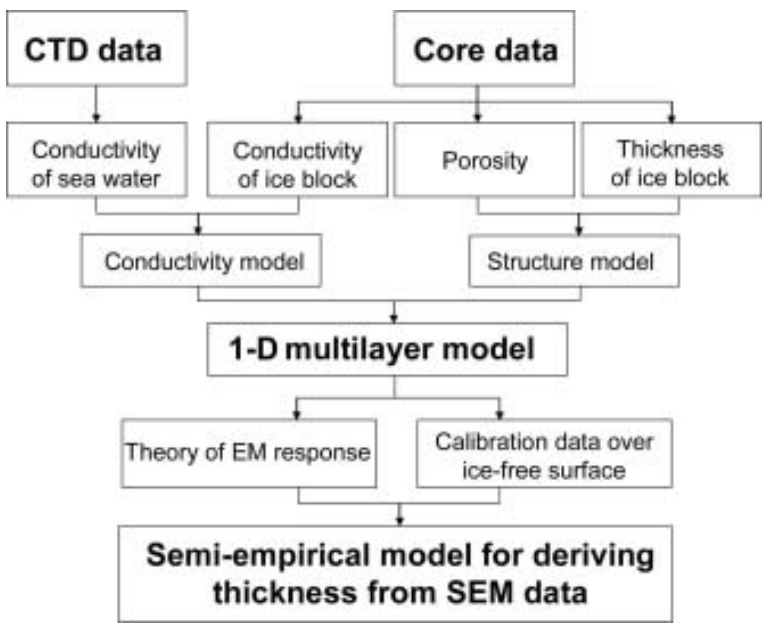

Fig. 4. Flow chart for developing model deriving total thickness from SEM response.

and conductivity-temperature-depth (CTD) observations. The combination of these two models provides a onedimensional (1-D), multilayer model expressing the structure of ice and sea water. A semi-empirical model is developed by combining this model, theoretical calculations and SEM responses over sea water.

\section{Analysis of sea-ice cores}

Twelve deformed ice cores are available in the present analysis. Figure 5 shows one result of the core analysis. $\sigma_{\text {ice }}$ is calculated as follows (Haas, 1998):

$$
\begin{aligned}
\sigma_{\text {ice }} & =\sigma_{\mathrm{b}} \nu_{\mathrm{b}}^{1.75} \\
\sigma_{\mathrm{b}} & =-T_{\text {ice }} \exp \left(0.5193+0.08755 T_{\text {ice }}\right) \\
\nu_{\mathrm{b}} & =\frac{\rho_{\text {ice }}}{1000} \frac{S_{\text {ice }}}{6.3415-16.767 T_{\text {ice }}} \times 100 .
\end{aligned}
$$

Here $T_{\text {ice, }} \rho_{\text {ice }}$ and $s_{\text {ice }}$ are temperature, density and salinity of sea ice, respectively. The thick-section photo indicates two discontinuities at 0.44 and $1.03 \mathrm{~m}$ below the top surface of ice. Figure 5 indicates that these discontinuities accompany high salinity, conductivity and temperature of ice. Thus it is judged that a sea-water- and/or slush-filled gap exist at these locations. These criteria are used as a judge of gap locations in deformed ice cores.

\section{Structure modeling}

Table 1 shows the summary of the core analysis of deformed ice. The ice thickness and snow depth range from 0.92 to $2.55 \mathrm{~m}$, and 0.06 to $0.27 \mathrm{~m}$, respectively. The thickness of the deformed ice is defined by the distance from the top surface of the ice to the bottom surface of the bottommost ice block. The thicknesses of the top consolidated layer, keel layer and ice blocks in a keel layer are derived using the criteria described above. Porosity is calculated as follows:

$$
\begin{aligned}
\text { Gap length } & =\text { Ice thickness }- \text { Total core length } \\
\text { Porosity } & =\frac{\text { Gap length }}{\text { Ice thickness }} \times 100 .
\end{aligned}
$$

Due to the difficulty of accurately measuring total core length, the scatter of porosity data is significant and one core has negative porosity. Thus the maximum, minimum and this negative value are omitted in averaging porosity. The
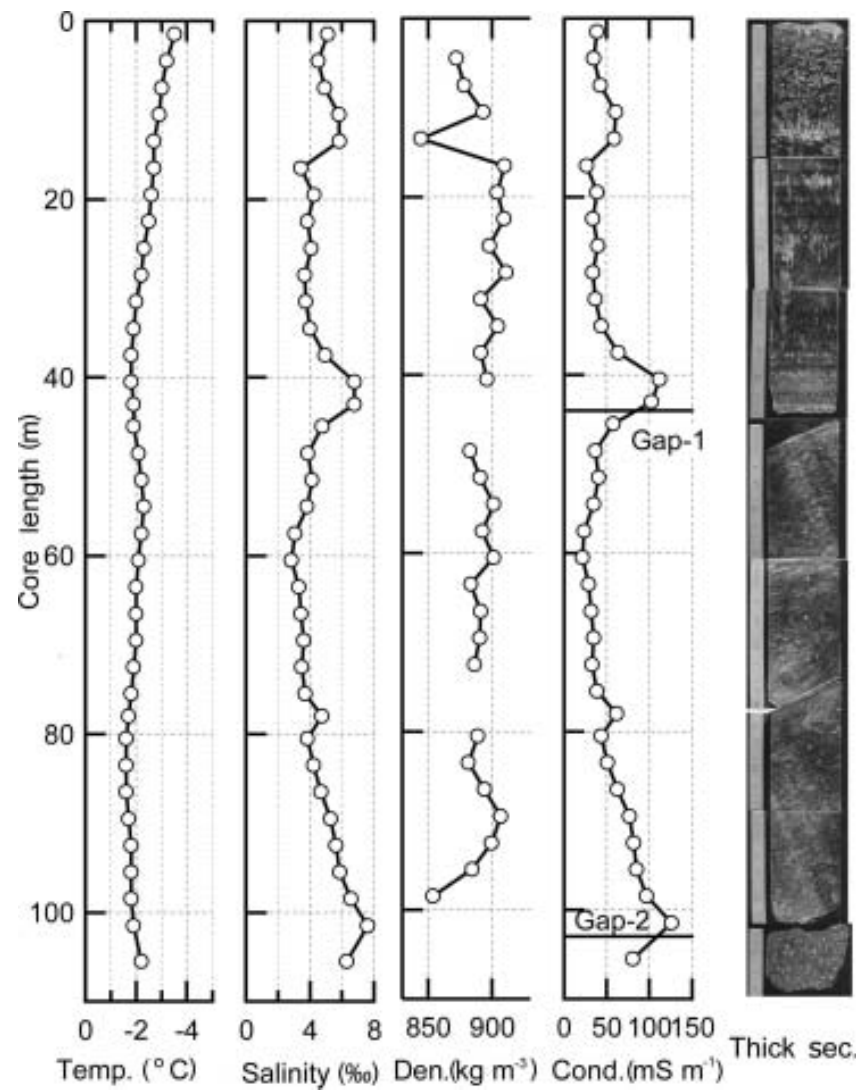

Fig. 5. Example of the results of ice-core analysis. Profiles of temperature, salinity and density are plotted against depth from top surface of ice. The conductivity of ice is calculated using Equations (2-4) and then plotted against depth from top surface of ice. Thick-section photo is also shown. Two horizontal lines in the conductivity panel indicate the estimated gap location.

average values are $0.14 \mathrm{~m}$ for snow depth, $0.64 \mathrm{~m}$ for top consolidated-layer thickness, $0.44-0.27 \mathrm{~m}$ for ice-block thickness in a keel layer and $13 \%$ for porosity.

\section{Conductivity modeling}

Figure 6 shows the relation between bulk ice conductivity and ice thickness. Here bulk means the depth-wise average. Bulk ice conductivity has a constant value of $50 \mathrm{mS} \mathrm{m}^{-1}$ for ice thicker than or equal to $0.17 \mathrm{~m}$. This is almost identical with values of winter and spring Antarctic first-year ice (35$75 \mathrm{mS} \mathrm{m}^{-1}$ ) reported by Worby and others (1999). CTD observations give the sea-water conductivity near the sea surface as $2700 \mathrm{mS} \mathrm{m}^{-1}$. It is assumed that the conductivity of a sea-water- or slush-filled gap inside deformed ice is the same as that of sea water.

\section{One-dimensional, multilayer modeling}

Combining structure and conductivity models, a onedimensional, multilayer model is proposed for representing the internal structure of sea ice in the southern Sea of Okhotsk. Figure 7 and Table 2 show the summary of the model. The snow layer and top consolidated layer are handled as a single layer. Each gap thickness is calculated by multiplying the porosity and the thickness of the ice layer above it. The thickness of the last ice layer is determined by the length to sea-water surface.

In the present model, up to four layers of ice and gaps are assumed in a keel layer. Including the top consolidated layer 


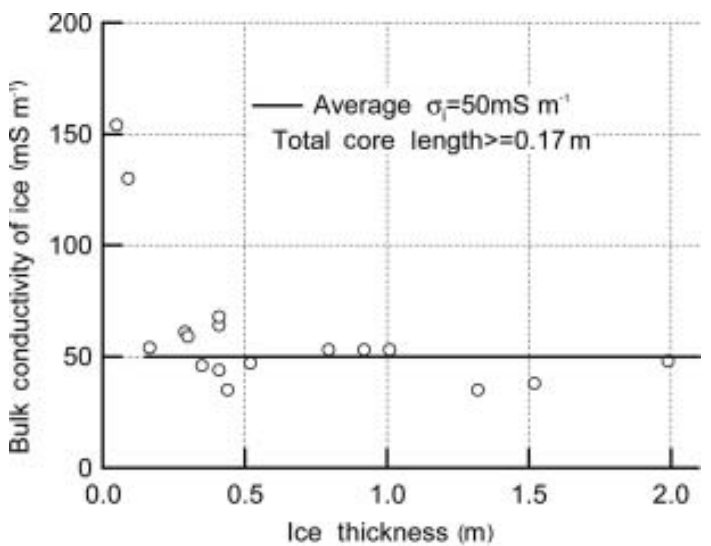

Fig. 6. Relation between bulk conductivity of ice and ice thickness.

and sea water, this model can treat ten layers at maximum. The influence of a highly conductive gap layer on the EM response decreases as thickness increases. Thus it is thought that the influence of this truncation is small.

\section{Forward modeling}

One-dimensional forward modeling of the EM response is performed by the full-solution multilayer analysis of Anderson (1979). A theoretical calculation program (PCLOOP, Geonics Ltd.) can provide transformation of $\sigma_{\mathrm{a}}$ into $Z_{\mathrm{E}}$. Firstly, the offset between theoretical calculations and measurements is evaluated as follows. During the voyages in 2004 and 2005, calibration of EM responses was conducted over sea water or nilas within pack ice twice, respectively. In these calibrations, the altitude of instruments was varied in a stepwise manner. The corresponding EM responses were calculated using PCLOOP by a onedimensional, one-layer model, representing sea water. The conductivity of sea water is set at $2700 \mathrm{mS} \mathrm{m}^{-1}$. Figure 8 shows the comparison of the results between calibrations in 2004 and theoretical calculations. The solid line denotes the curve fitting of calibration data by exponential function (denoted as ice-free model). Although calculations should be identical with measurements, there exists a certain

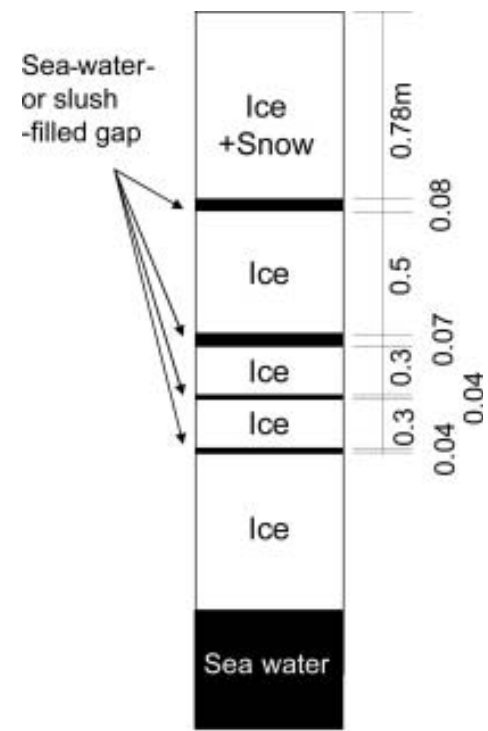

Conductivity of ice and snow
\[ \begin{aligned} & =50 \mathrm{mS} \mathrm{m}^{-1}\end{aligned} \]
$\begin{aligned} & \text { Conductivity of sea water } \\ & \text { and gap }=2700 \mathrm{mS} \mathrm{m}^{-1}\end{aligned}$

Fig. 7. One-dimensional multilayer model, expressing sea water and internal structure of sea ice.

amount of offset, probably due to the misalignment of the EM instrument. Thus modeled responses $\left(\sigma_{\mathrm{am}}\right)$ are corrected by Equations (7) and (8) in the following analysis:

$$
\begin{aligned}
\Delta \sigma_{\mathrm{a}}\left(Z_{\mathrm{E}}\right) & =\sigma_{\mathrm{a}}\left(Z_{\mathrm{E}}\right)-\sigma_{\mathrm{am}}\left(Z_{\mathrm{E}}\right) \quad \text { over ice-free water } \\
\sigma_{\mathrm{am} \_ \text {correct }} & =\sigma_{\mathrm{am}}+\Delta \sigma_{\mathrm{a}}\left(Z_{\mathrm{E}}\right) .
\end{aligned}
$$

During voyages in 2004 and 2005, calibration of EM responses over deformed ice was conducted twice and once, respectively. Figure $9 \mathrm{a}$ and $\mathrm{b}$ show the comparison of responses between measurements and calculations in 2004 and 2005, respectively. The total thickness of ice was 2.48 and $2.24 \mathrm{~m}$ in 2004 and $2.14 \mathrm{~m}$ in 2005 . The ice-free model is often used as a transformation formula from $\sigma_{\mathrm{a}}$ to $Z_{\mathrm{E}}$. This is valid in the case of solid ice since the bulk conductivity of

\begin{tabular}{|c|c|c|c|c|c|c|c|c|c|c|c|}
\hline \multirow[t]{2}{*}{ Core No. } & \multirow{2}{*}{$\begin{array}{c}\text { Snow depth } \\
\text { m }\end{array}$} & \multirow{2}{*}{$\begin{array}{c}\text { Ice } \\
\text { thickness } \\
\text { m }\end{array}$} & \multirow{2}{*}{$\begin{array}{c}\text { Total core } \\
\text { length } \\
\text { m }\end{array}$} & \multirow{2}{*}{$\begin{array}{c}\text { Gap length } \\
\text { m }\end{array}$} & \multirow{2}{*}{$\begin{array}{c}\text { Top-layer } \\
\text { thickness } \\
\text { m }\end{array}$} & \multirow{2}{*}{$\begin{array}{c}\text { Keel-layer } \\
\text { thickness } \\
\text { m }\end{array}$} & \multirow{2}{*}{$\begin{array}{c}\text { Porosity } \\
\text { \% }\end{array}$} & \multicolumn{4}{|c|}{ Thickness of ice block(s) in keel layer } \\
\hline & & & & & & & & $\mathrm{m}$ & $\mathrm{m}$ & $\mathrm{m}$ & $\mathrm{m}$ \\
\hline 0311 & 0.12 & 1.01 & 1.08 & -0.07 & 0.44 & 0.57 & -7 & 0.64 & & & \\
\hline 0312 & 0.06 & 0.92 & 0.90 & 0.02 & 0.41 & 0.51 & 2 & 0.49 & & & \\
\hline 0315 & 0.19 & 1.42 & 1.04 & 0.38 & 0.63 & 0.79 & 27 & 0.32 & 0.09 & & \\
\hline 0316 & 0.10 & 1.82 & 1.62 & 0.20 & 0.21 & 1.61 & 11 & 0.79 & 0.33 & 0.11 & 0.18 \\
\hline 0401 & 0.20 & 2.13 & 1.96 & 0.17 & 0.94 & 1.19 & 8 & 0.15 & 0.27 & 0.30 & 0.30 \\
\hline 0402 & 0.27 & NA & 2.26 & NA & 0.21 & NA & NA & 1.52 & 0.18 & 0.35 & \\
\hline 0403 & 0.20 & 2.55 & 2.09 & 0.46 & 0.73 & 1.82 & 18 & 0.08 & 0.37 & 0.53 & 0.38 \\
\hline 0404 & 0.06 & 1.55 & 1.32 & 0.23 & 0.52 & 1.03 & 15 & 0.36 & 0.44 & & \\
\hline 0406 & 0.13 & 1.32 & 1.30 & 0.02 & 1.10 & 0.21 & 2 & 0.20 & & & \\
\hline 0407 & 0.08 & 1.52 & 1.28 & 0.24 & 1.03 & 0.49 & 16 & 0.25 & & & \\
\hline 0408 & 0.16 & 2.20 & 2.11 & 0.09 & 0.92 & 1.28 & 4 & 0.15 & 0.45 & 0.59 & \\
\hline Mean & 0.14 & & & & 0.64 & & 13 & 0.44 & 0.27 & 0.36 & 0.29 \\
\hline
\end{tabular}

Table 1. Summary of core analysis of deformed ice

Notes: Italic indicates the data omitted in averaging. Porosity is defined as the ratio of gap length to total thickness. NA: not applicable. 


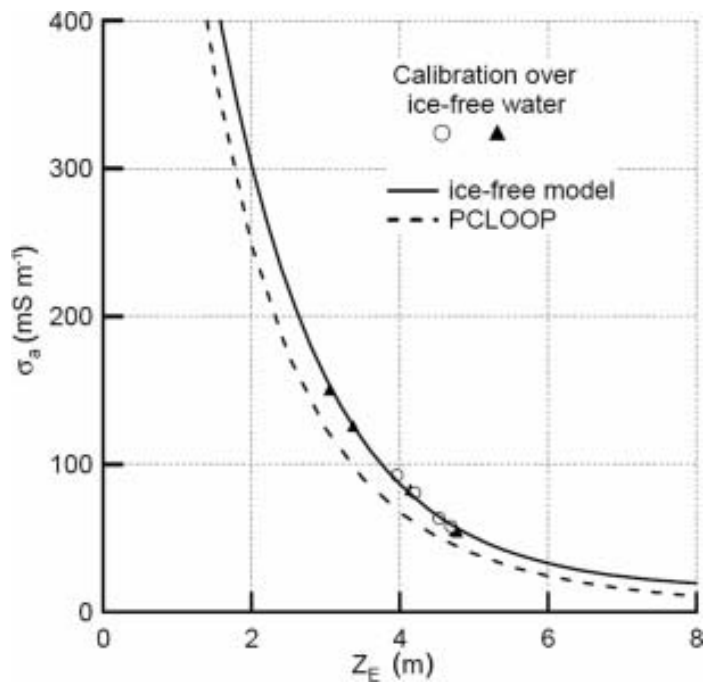

Fig. 8. Offset between theoretical calculations and measurements. Two symbols denote the results by calibration over sea water in 2004. The solid line denotes the curve fitting of these data by exponential function. Dashed line indicates the result of PCLOOP by using one-dimensional one-layer model representing sea water. The conductivity of sea water is $2700 \mathrm{mS} \mathrm{m}^{-1}$.

sea ice is very small compared to that of sea water. However, there is a large offset between calibration data and the icefree model. This is primarily due to the existence of a highly conductive layer in the deformed ice.

Modeled responses in 2004 show reasonable agreement with calibration data. However, modeled responses were underestimated against observations in 2005. This is most likely due to the very high porosity of ice at the calibration site. The core (No. 0502 in Table 1) had porosity of 38\%, the highest value in 3 years. However, the modeled response approaches the observed response with an increase of $Z_{\mathrm{E}}$. The sensor height $\left(Z_{\mathrm{L}}\right)$ was normally about $4 \mathrm{~m}$ during observations. Thus $2.14 \mathrm{~m}$ thick ice gives $Z_{\mathrm{E}}$ of $6.14 \mathrm{~m}$, and the difference of responses is small under such normal observation conditions.

\section{Inversion}

A series of calculations by the forward modeling are conducted by changing $Z_{\mathrm{L}}$ and $Z_{\mathrm{I}}$. The range of $Z_{\mathrm{L}}$ and $Z_{\mathrm{I}}$ is 1.0 $5.5 \mathrm{~m}$ and $0.0-5.0 \mathrm{~m}$, respectively. The increment in $Z_{\mathrm{L}}$ and

Table 2. Thickness and conductivity of each layer

\begin{tabular}{lcr}
\hline & Thickness & Conductivity \\
& $\mathrm{m}$ & $\mathrm{mS} \mathrm{m}^{-1}$ \\
\hline Snow layer & 0.14 & 50 \\
Top ice layer & 0.64 & 50 \\
1st gap & 0.08 & 2700 \\
1st ice layer & 0.50 & 50 \\
2nd gap & 0.07 & 2700 \\
2nd ice layer & 0.30 & 50 \\
3rd gap & 0.04 & 2700 \\
3rd ice layer & 0.30 & 50 \\
4th gap & 0.04 & 2700 \\
4th ice layer & To sea-water surface & 50 \\
Sea water & Infinite & 2700 \\
& & \\
\hline
\end{tabular}
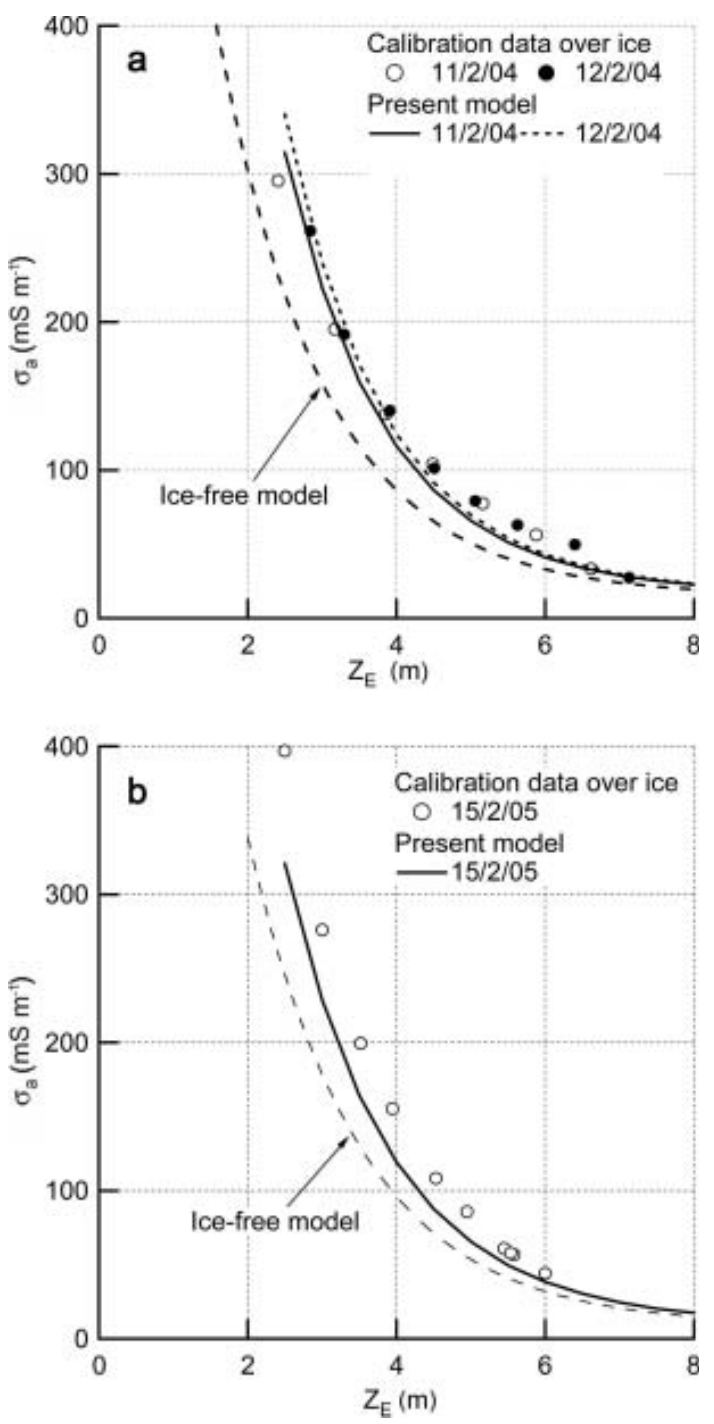

Fig. 9. Validity of the present model: results in (a) 2004 and (b) 2005. Responses using the present model are compared with those observed by calibration over two (a) and one (b) deformed ice floes. Dashed line indicates the ice-free model, given by the least-squares fitting of calibration data over ice-free water. Dates are $\mathrm{dd} / \mathrm{m} / \mathrm{yy}$.

$Z_{\mathrm{I}}$ is $0.1 \mathrm{~m}$. Calculated responses are corrected to $\sigma_{\text {am_correct }}$ using Equation (8). A look-up table consists of 46 by 51 $\sigma_{\text {am_correct }}$. Total thickness is obtained by matching measured $\sigma_{\mathrm{a}}$ and $Z_{\mathrm{L}}$ with values in this table. If total thickness is $<0.78 \mathrm{~m}$, the ice is regarded as level and treated by a twolayer model, i.e. one layer for ice and another for sea water. The number of layers depends on the total thickness but is truncated to be ten.

\section{RESULTS AND DISCUSSIONS Validity of the model}

The present model has the following morphological parameters of ice: thickness of the top consolidated layer, porosity and thickness of the ice blocks in a keel layer. Toyota and others (2004b) analyzed the video thickness data collected from 1991 to 2000, except 1995, from late January to late February in the southern Sea of Okhotsk. They reported that the annually averaged ice thickness ranges from 0.19 to $0.55 \mathrm{~m}$. This thickness is regarded as that of the level ice or the top consolidated layer of deformed ice. The 


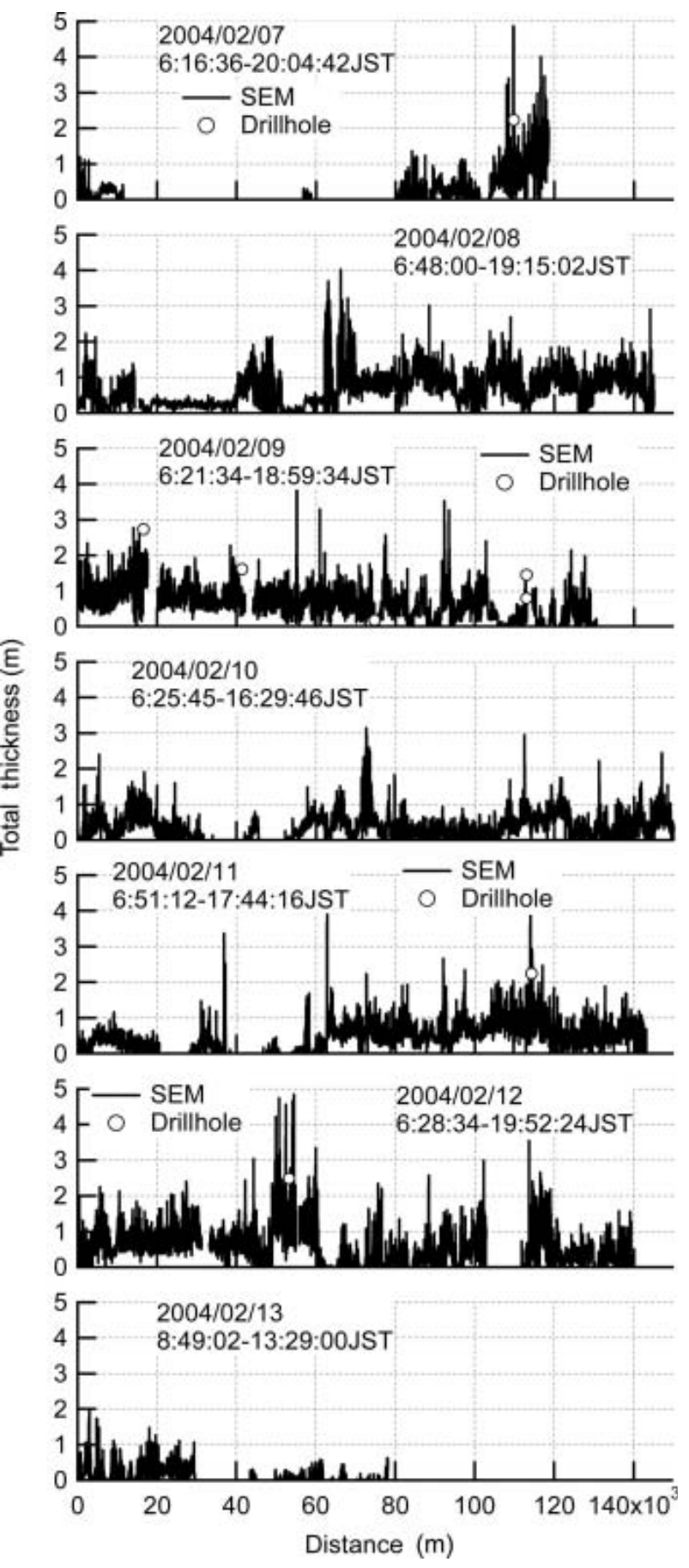

Fig. 10. Total thickness profiles by SEM during voyages in 2004. The solid line indicates total thickness by SEM. Circles indicate total thickness by drillhole observations. Dates are yyyy/mm/dd. JST: Japan Standard Time.

modeled thickness of the top consolidated layer $(0.64 \mathrm{~m})$ is over the maximum of annually averaged ice thickness. This means the possibility of misinterpreting level ice as deformed ice is quite low, guaranteeing the accuracy of levelice thickness in the present model.

In general, the porosity of a keel layer of fresh hummocks and ridges is about $20-40 \%$ (Leppäranta, 2005). Beketsky and others (1996) reported that the porosity of a keel layer and an entire hummock offshore of northern Sakhalin was $20 \%$ and $13 \%$, respectively. The present model gives the porosity of the entire deformed ice as $13 \%$ and that of a keel layer as $23 \%$. These values are within the range of fresh

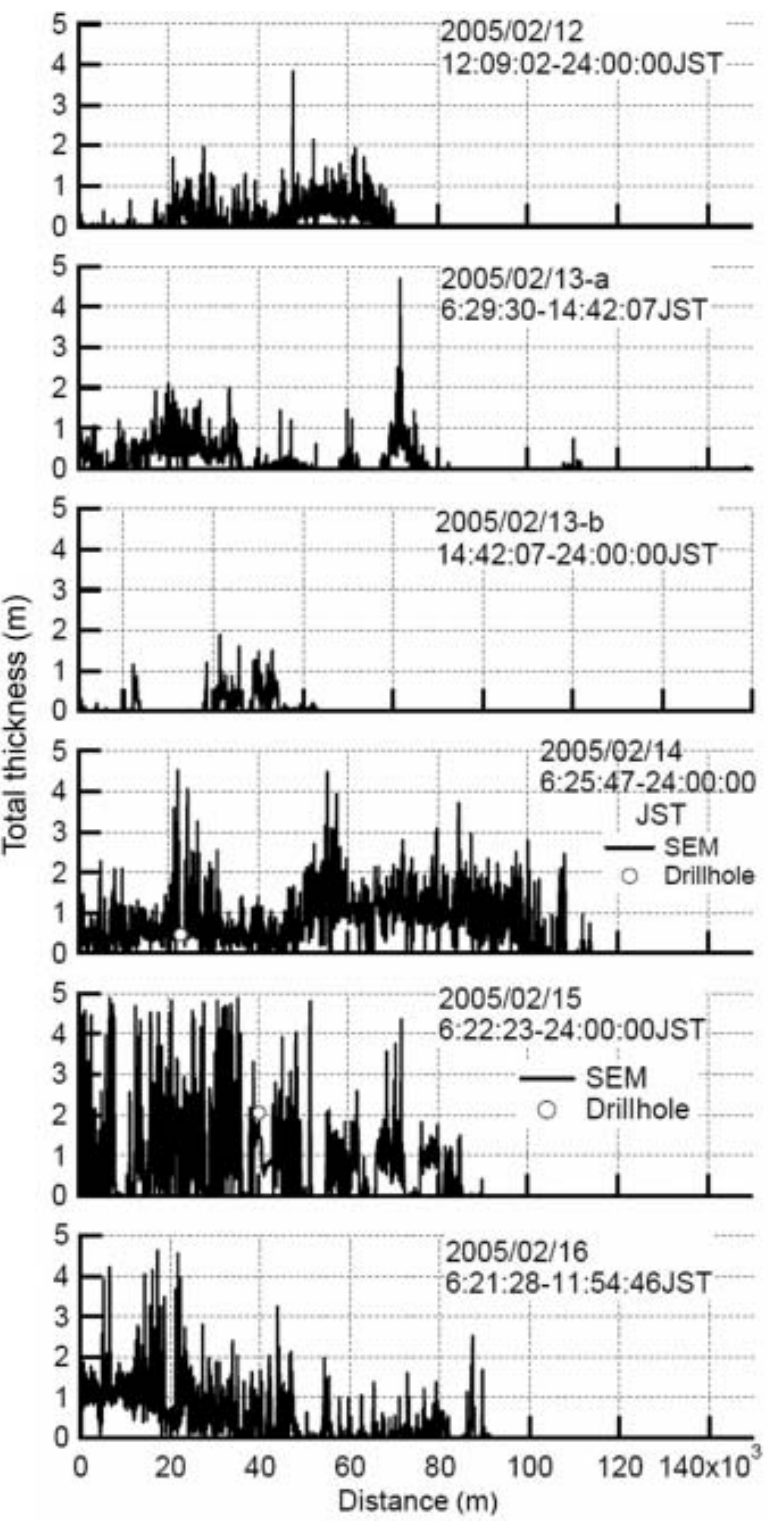

Fig. 11. Same as Figure 10, but for 2005. Profiles on 13 February are divided into two graphs.

hummocks and ridges and close to the values by Beketsky and others (1996). The thickness of the ice blocks in a keel layer is highly dependent on the mechanism of ridge or hummock formation. More data on the keel-layer structure need to be collected in order to validate the present model.

\section{Profiles of total thickness}

Figures 10 and 11 show the total thickness distributions in 2004 and 2005, respectively. A profile on each day is plotted against distance. The origin of distance is defined at the location where SEM observations started. Smoothed data in $10 \mathrm{~s}$ are plotted at $2 \mathrm{~s}$ intervals. During voyages, simultaneous observations of ice thickness were conducted by using a downward-looking video (Uto and others, 1999; Toyota and others, 2004b) and by drillhole observations.

Figure 12 shows the comparison of total thickness between SEM and the video method. Both datasets on 9 February 2004 are plotted. Video observations have no total thickness exceeding $1.5 \mathrm{~m}$, although a general trend between the two datasets is apparent. Figure 13 shows the correlation of total thickness between SEM and video 


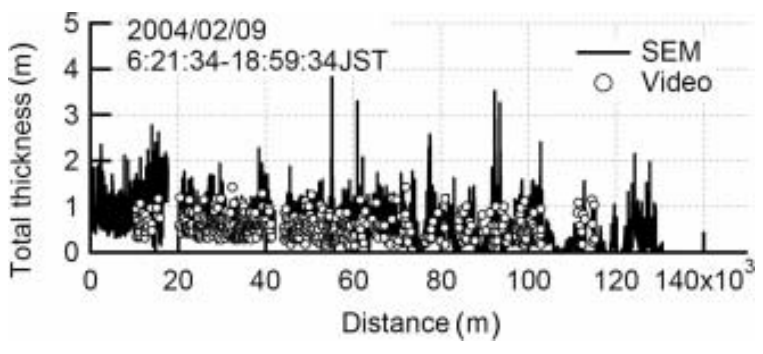

Fig. 12. Comparison of total thickness between SEM and video method on 9 February 2004. The solid line and circles indicate the total thickness by SEM and video observations, respectively.

observations on 9 February 2004. Here both datasets are averaged in $1 \mathrm{~km}$ segments. It is clearly shown that video observations underestimate the total thickness against SEM. This is due to the limitation of video observations. In the video method, sea-ice thickness is measured from floes turned into side-up positions. In most cases, a loose keel layer of deformed ice is lost during turning. Thus the video method mostly observes the thickness of level ice or the top consolidated layer of deformed ice.

In Figures 10 and 11, total thicknesses by drillhole observations are also plotted. Both datasets agree fairly well and SEM provides less total thickness than drillhole observations in some cases. This is probably due to the large footprint of SEM observations. For example, SEM has a footprint with a diameter of about $8 \mathrm{~m}$ for observing $2 \mathrm{~m}$ thick ice at the normal sensor altitude. Furthermore data are time-averaged in $10 \mathrm{~s}$ increments. These two factors lead to smoothing of local peaks in total thickness profiles.

\section{Probability density of total thickness}

Figure 14 shows the probability density function (PDF) of total thickness by SEM observations. PDFs are derived from all data in 2004 and 2005. The average total thickness of ice thicker than $0.05 \mathrm{~m}$ is 0.61 and $0.75 \mathrm{~m}$ in 2004 and 2005, respectively. The maximum total thickness is 4.49 and $4.87 \mathrm{~m}$ in 2004 and 2005, respectively.

Figure $14 \mathrm{~b}$ indicates that modal thickness in the PDF of 2004 is $0.2-0.3 \mathrm{~m}$, which corresponds to young ice presumably frozen in situ. Two more peaks appear in the ranges $0.5-0.6$ and $0.9-1.0 \mathrm{~m}$. The former peak corresponds to the maximum thickness of level ice (Uto and others, 1999) in the southern Sea of Okhotsk. The latter peak corresponds to modal thickness in the range of deformed ice. In 2005, there is no peak in the range of young ice. The modal thickness is $0.4-0.5 \mathrm{~m}$, which corresponds to the typical thickness of level ice. The second peak is found in the range $1.0-1.1 \mathrm{~m}$. This is the modal thickness in the range of deformed ice in 2005.

Both PDFs have a tail which gives a good fit to a negative exponential distribution. Interestingly, the same trend is reported for the distributions of Arctic sea-ice thickness (Wadhams, 2000). The slope of a tail expresses the amount of deformed ice. It is clearly observed that the amount of deformed ice was larger in 2005 and that of thin level ice was larger in 2004. Thus it is speculated that in situ freezing is dominant in 2004 and southward drift of thick deformed ice is dominant in 2005 .

In summary, there are one or two peaks within the range of level ice. The main peak is in the range $0.4-0.6 \mathrm{~m}$, which

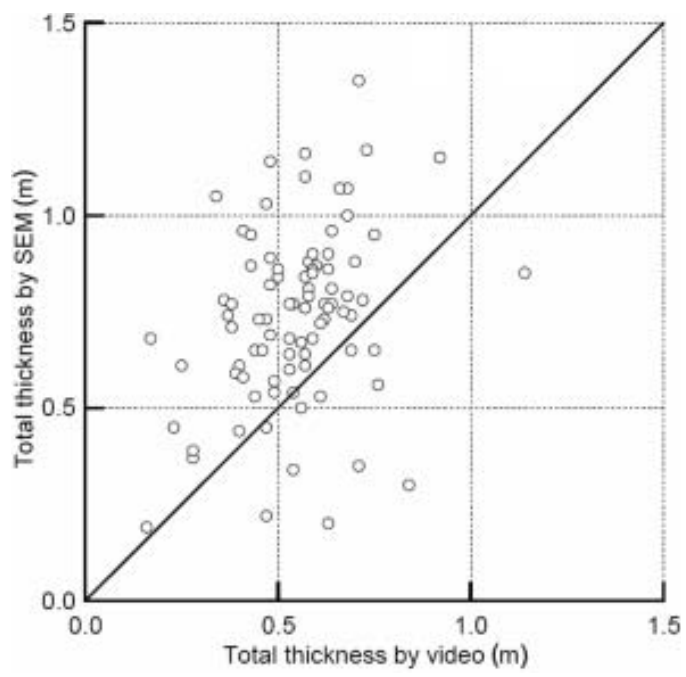

Fig. 13. Correlation of total thickness between SEM and video observations. on 9 February 2004. Both datasets are averaged in $1 \mathrm{~km}$ segments.
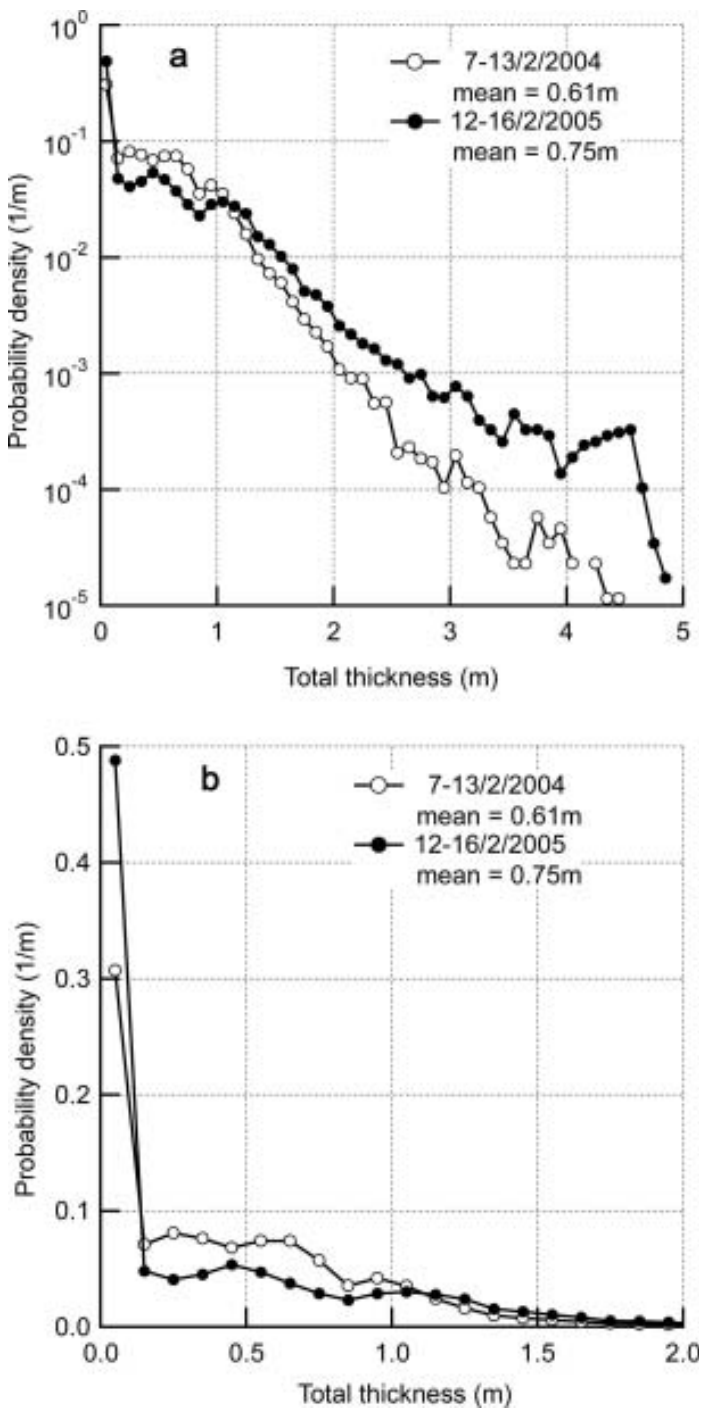

Fig. 14. PDF of total thickness by SEM observations in 2004 (empty circles) and 2005 (filled circles): (a) semi-log plot in the total thickness of $0-5 \mathrm{~m}$; (b) linear plot in the total thickness of $0-2 \mathrm{~m}$. PDF is derived from all data measured in 2004 and 2005 . Bin is set $0.1 \mathrm{~m}$. 
is almost identical with mean annual maximum thickness of thermally grown ice in the southern Sea of Okhotsk (Fukutomi, 1952). The most frequent thickness in the range of deformed ice is $0.9-1.1 \mathrm{~m}$, which represents the typical thickness of moderately deformed ice. A larger amount of thick deformed ice leads to a lesser amount of thin level ice in 2005, and vice versa in 2004.

\section{CONCLUSION}

We propose a new model for deriving total thickness by SEM observations in the southern Sea of Okhotsk. Special attention is given to observations of total thickness of deformed ice with better accuracy. Based on the results of core analysis, we express the internal structure of pack ice in the southern Sea of Okhotsk, as a one-dimensional multilayered structure. Combining this model with theoretical calculation, a new algorithm is developed for deriving total thickness from responses of SEM instruments. The validity of the morphological parameters of ice used in this model is discussed. The thickness of the top consolidated layer is over the maximum of the annually averaged ice thickness observed from 1991 to 2000. This means the possibility of misinterpreting level ice as deformed ice is quite low. Comparison with results by video observations shows an underestimation of total thickness by the video method. This is primarily because of the limitation of total thickness observations by the video method. Comparison with drillhole observations shows fair agreement. The PDF of total thickness reveals the characteristics of the total thickness distribution. There are two characteristic ranges of thickness. One is $0.4-0.6 \mathrm{~m}$, a modal thickness of level ice. In the range of deformed ice, there is a peak at $0.9-1.1 \mathrm{~m}$ thickness, which represents the typical thickness of moderately deformed ice observed in the southern Sea of Okhotsk. A larger amount of thick deformed ice leads to a lesser amount of thin level ice in 2005, and vice versa in 2004.

\section{ACKNOWLEDGEMENTS}

We acknowledge the captains and the crew of icebreaker Soya of the Japan Coast Guard for their kind cooperation. We also thank K.I. Ohshima of the ILTS, M. Nakayama of Kushiro Children's Museum, K. Naoki of Chiba University, and S. Oka and T. Takimoto of the NMRI for their efforts in conducting field observation.

\section{REFERENCES}

Anderson, W.L. 1979. Computer program: numerical integration of related Hankel transforms of orders 0 and 1 by adaptive digital filtering. Geophysics, 44(7), 1287-1305.

Beketsky, S.P., V.N. Astafiev and P.A. Trusckov. 1996. Structure of hummocks offshore of Northern Sakhalin. In Proceedings of the 6th International Offshore and Polar Engineering Conference. Vol. 2. Los Angeles, CA, International Society of Offshore and Polar Engineers, 398-400.

Fukamachi, Y., G. Mizuta, K.I. Ohshima, H. Melling, D. Fissel and M. Wakatsuchi. 2003. Variability of sea-ice draft off Hokkaido in the Sea of Okhotsk revealed by a moored ice-profiling sonar in winter of 1999. Geophys. Res. Lett., 30(7), 1376. (10.1029/ 2002GL016197.)

Fukutomi, T. 1952. Study of sea-ice (the 17th report). On the maximum thickness of winter ice at northern seacoasts. Low Temp. Sci., Ser. A, 9, 125-136. [In Japanese.]

Haas, C. 1998. Evaluation of ship-based electromagnetic-inductive thickness measurements of summer sea-ice in the Bellingshausen and Amundsen Seas, Antarctica. Cold Reg. Sci. Technol., 27(1), 1-16.

Kovacs, A., J.S. Holladay and C.J. Bergeron, Jr. 1995. Footprint/ altitude ratio for helicopter electromagnetic sounding of sea-ice thickness: comparison of theoretical and field estimates. Geophysics, 60(2), 374-380.

Leppäranta, M. 2005. The drift of sea ice. Berlin, etc., SpringerVerlag.

Parkinson, C.L., D.J. Cavalieri, P. Gloersen, H.J. Zwally and J.C. Comiso. 1999. Arctic sea ice extents, areas, and trends, 1978-1996. J. Geophys. Res., 104(C9), 20,837-20,856.

Tateyama, K., S. Uto, K. Shirasawa and H. Enomoto. 2004. Electromagnetic-inductive measurements for the undeformed and deformed sea-ice and snow in the East Antarctic. In Chung, J.S., K. Izumiyama, M. Sayed and S.W. Hong, eds. Proceedings of the 14th International Offshore and Polar Engineering Conference. Vol. I. Toulon, International Society of Offshore and Polar Engineers, 806-812. CD-ROM.

Toyota, T., S. Takatsuji, K. Tateyama, M. Nakayama, K. Naoki and K.I. Ohshima. 2004a. Properties of thick sea ice and overlying snow in the southern Sea of Okhotsk. In Ivashintsov, D., ed. Proceedings of the 17th International Symposium on Ice. Vol. 1., St Petersburg, International Association of Hydraulic Engineering and Research, 406-412.

Toyota, T., T. Kawamura, K.I. Ohshima, H. Shimoda and M. Wakatsuchi. 2004b. Thickness distribution, texture and stratigraphy, and a simple probabilistic model for dynamical thickening of sea ice in the southern Sea of Okhotsk. J. Geophys. Res., 109(C6), C06001. (10.1029/2003JC002090.)

Uto, S., H. Shimoda and K. Tamura. 1999. Ship-based sea ice observations in the southernmost part of the Sea of Okhotsk. In Tuhkuri, J. and K. Riska, eds. Proceedings of the 15th International Conference on Port and Ocean Engineering under Arctic Conditions. Vol. 1. Helsinki, Helsinki University of Technology. Ship Laboratory, 380-388.

Wadhams, P. 2000. Ice in the ocean. Amsterdam, etc., Gordon and Breach Science Publishers.

Worby, A.P. 1999. Observing Antarctic sea ice: a practical guide for conducting sea ice observations from vessels operating in the Antarctic pack ice. Hobart, Scientific Committee for Antarctic Research. Global Change and the Antarctic Program. CD-ROM.

Worby, A.P., P.W. Griffin, V.I. Lytle and R.A. Massom. 1999. On the use of electromagnetic induction sounding to determine winter and spring sea ice thickness in the Antarctic. Cold Reg. Sci. Technol., 29(1), 49-58. 